\title{
Operational temporary speed reductions on the ETCS-DMI
}

\author{
D. Emery \\ LITEP Group, École Polytechnique Fédérale de Lausanne, Switzerland
}

\begin{abstract}
Dealing with a congested railway area becomes an important topic in railway operation management. Significant efforts are made to develop a Driver Advisory System (DAS) in connection with the trackside Train Management System (TMS). Many advantages are expected from smoothing train dynamic speed profiles: timetable resilience, significant reduction of both the energy consumption and the wear and tear and, finally, positive impacts on the comfort for passengers. Today, on the one hand, only a few Centrally Guided Train Operation Systems (CGTO) are already in operation on European major railways. On the other hand, the European Train Control System (ETCS) spreads rapidly. Such combination offers a great opportunity to promote a European standard CGTO system using the ETCS-DMI opportunities.

The present paper describes many options using either the "Monitoring" area, or the "Supplementary Driving Info" area, or the "Planning" area, or the "Speed Info" area; or a combination of them on the ETCS Diver Machine Interface (DMI). Some of them give only advices or guidance but some of them indicate operational temporary speed reductions (O_TSR) that are mandatory.

Historical research, current experiments, and dispatching concepts in bottlenecks areas militate in favour of the compulsory character of temporary speed limits due to congestion. Therefore, the last option presented here should be more examined more in depth.

Keywords: ETCS, DMI, DAS, CGTO, speed guidance, operational TSRs.
\end{abstract}

\section{Introduction}

On the one hand, the Driver Advisory Speed (DAS) concept has already a long history. Specific lateral signals were used in many rail networks to order drivers 
to speed up or slow down the train preventively due to a potential conflict situation far ahead. Such signalling combines positive aspects: minimising the global delay of trains, reducing energy consumption as well as tear and wear.

On the other hand, the ETCS-DMI has a long future ahead. It becomes therefore important to introduce, as soon as possible, a common standard for the connection of a DAS to the ETCS-DMI, in order to provide information from the Train Management System (TMS) to the driver.

However, what is the final goal of a Centrally Guided Train Operation System (CGTO)? Only giving information or guidance? Or giving speed orders that must be obeyed?

This paper proposes some options to develop a standard CGTO and to answer to the question above.

\section{Speed representations in the ETCS-DMI and human factors}

The default window of ETCS-DMI is divided in many rectangular areas. The "Supervised Distance Info"(A), "Speed Info"(B), "Supplementary Driving Info" (C), "Planning" (D) and "Monitoring" (E) areas are concerned by this study.

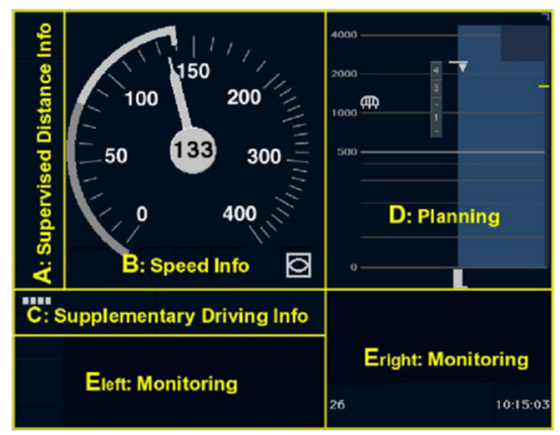

Figure 1: Respective positions of the areas of a ETCS-DMI display.

These areas are used for speed and supervision information. The main focus of the driver is on the "Speed info" area, which displays namely the actual speed, the speed limit, and the level of speed supervision. As soon as the train approaches a speed reduction, the driver widens slightly its focus to encompass the "Supervised Distance Info" area, which gives some information needed for convenient braking. The peripheral view can also catch what is displayed by the "Supplementary Driving Info" area, like the red symbol of a system brake intervention or the yellow symbol of the announcement of a tunnel that is a non-stopping area.

Before choosing ETCS-DMI Speed Advice or Speed Guidance colours, it is necessary to take into account both the ETCS colour philosophy and the way the drivers react to colours displayed on the ETCS-DMI, in particular those appearing in the "Speed Info" area. 


\subsection{Colour and sound philosophy}

"Grey" is the colour of normality. The Ceiling Speed Monitoring (CSM) is the normal driving situation as long as a compulsory speed reduction isn't foreseen. The Circular Speed Gauge (CSG) is "dark grey" and the speed pointer is "grey". These colours stay unchanged in the Target Speed Monitoring (TSM) situation as long as there is no need to notify the reduction of the actual speed of the train.

"Yellow" is the colour of a speed reduction warning. This colour appears in the TSM situation when, according to the actual speed of the train, speed reduction has to be proceeded. Upon entering this status, the audible information Sinfo is played.

"Orange" is the colour of overspeed warning. This colour is used as soon as the actual speed of the train is higher than the Most Restrictive Dynamic Speed Profile (MRDSP). Upon entering this status, the audible information S1_toofast info is played. When the "Orange" colour is near changing to "Red" the audible information S2_warning info is played.

"Red" is the colour of system intervention. This colour indicates, in speed topics, the overtaking of the overspeed tolerance. In this situation, the system brakes the train by itself.

Table 1: Conditions for display and colour of the speed pointer in FS mode when Vrelease does not exist [1].

\begin{tabular}{|l|c|c|c|c|}
\hline $\begin{array}{l}\text { Supervision } \\
\text { Status }\end{array}$ & $\begin{array}{c}0 \leq \text { pointer } \\
\leq \mathrm{V}_{\text {perm }}\end{array}$ & $\begin{array}{c}0 \leq \text { pointer } \\
<\mathrm{V}_{\text {target }}\end{array}$ & $\begin{array}{c}\mathrm{V}_{\text {target }} \leq \text { pointer } \leq \\
\mathrm{V}_{\text {perm }}\end{array}$ & $\begin{array}{c}\text { pointer } \\
\mathrm{V}_{\text {perm }}\end{array}$ \\
\hline CSM - NoS & Grey & - & - & - \\
\hline CSM - OvS/WaS & - & - & - & Orange \\
\hline CSM - IntS & Grey & - & - & Red \\
\hline TSM - IndS & - & Grey & Yellow & - \\
\hline TSM - OvS/WaS & - & - & - & Orange \\
\hline TSM - IntS & - & Grey & Yellow & Red \\
\hline
\end{tabular}

Table 2: $\quad$ Conditions for display and colour of CSG in FS mode when Vrelease does not exist [1].

\begin{tabular}{|l|c|c|c|c|}
\hline $\begin{array}{l}\text { Supervision } \\
\text { Status }\end{array}$ & $\begin{array}{c}0 \leq \mathrm{CSG} \\
\leq \mathrm{V}_{\text {perm }}\end{array}$ & $\begin{array}{c}0 \leq \mathrm{CSG} \\
<\mathrm{V}_{\text {target }}\end{array}$ & $\begin{array}{c}\mathrm{V}_{\text {target }} \leq \mathrm{CSG} \\
\leq \mathrm{V}_{\text {perm }}\end{array}$ & $\begin{array}{c}\mathrm{V}_{\text {perm }}<\mathrm{CSG} \\
\leq \mathrm{V}_{\text {SBI }}\end{array}$ \\
\hline CSM - NoS & Dark Grey & - & - & - \\
\hline CSM - OvS/WaS & Dark Grey & - & - & Orange \\
\hline CSM - IntS & Dark Grey & - & - & Red \\
\hline TSM - IndS & - & Dark Grey & Yellow & - \\
\hline TSM - OvS/WaS & - & Dark Grey & Yellow & Orange \\
\hline TSM - IntS & - & Dark Grey & Yellow & Red \\
\hline
\end{tabular}


Table 3: Definition of ETCS-DMI (left) and NTC (right) additional colours (Red/Green/Blue) [1].

\begin{tabular}{|l|l|}
\hline Colour name & $\begin{array}{l}\text { Red/Green } \\
\text { Blue }\end{array}$ \\
\hline Yellow & $223 / 223 / 0$ \\
\hline Orange & $234 / 145 / 0$ \\
\hline Red & $191 / 0 / 2$ \\
\hline Dark Blue & $3 / 17 / 34$ \\
\hline Shadow & $8 / 24 / 57$ \\
\hline PASP dark & $33 / 49 / 74$ \\
\hline PASP light & $41 / 74 / 107$ \\
\hline White & $255 / 255 / 255$ \\
\hline Grey & $195 / 195 / 195$ \\
\hline $\begin{array}{l}\text { Medium } \\
\text { Grey }\end{array}$ & $150 / 150 / 150$ \\
\hline Dark Grey & $85 / 85 / 85$ \\
\hline Black & $0 / 0 / 0$ \\
\hline
\end{tabular}

\begin{tabular}{|l|l|}
\hline $\begin{array}{l}\text { Colour } \\
\text { name }\end{array}$ & $\begin{array}{l}\text { Red/Green } \\
\text { /Blue }\end{array}$ \\
\hline Blue & $0 / 0 / 234$ \\
\hline Green & $0 / 234 / 0$ \\
\hline Light Red & $255 / 96 / 96$ \\
\hline Light Green & $96 / 255 / 96$ \\
\hline
\end{tabular}

SBB (2006):
\begin{tabular}{|l|l|}
\hline $\begin{array}{l}\text { Very Light } \\
\text { Grey }\end{array}$ & $215 / 251 / 215$ \\
\hline $\begin{array}{l}\text { Dark } \\
\text { Yellow }\end{array}$ & $105 / 105 / 0$ \\
\hline Magenta & $255 / 0 / 255$ \\
\hline
\end{tabular}

\section{SNCF}

(2015):

\begin{tabular}{|l|l|l|}
\hline $\begin{array}{l}\text { NExTEO } \\
\text { Blue }\end{array}$ & $63 / 173 / 255$ \\
\hline
\end{tabular}

\subsection{Driving styles}

The Target Speed Monitoring (TSM) is the situation when the speed limit of the train has to be reduced. Depending on the speed of the train at that time and the driving style taught to the drivers, drivers will react very differently. According to table 4 , three main driving styles can be distinguished. In this paragraph, no energy saving consideration is taken into account.

Table 4: Colour and driving style.

\begin{tabular}{|l|c|c|c|}
\hline $\begin{array}{l}\text { Driving style } \\
\text { before/during a } \\
\text { speed reduction }\end{array}$ & $\begin{array}{c}\text { Alternate } \\
\text { driving style } \\
\text { description }\end{array}$ & $\begin{array}{c}\text { Subjective } \\
\text { appreciation }\end{array}$ & Consequence \\
\hline "dark grey" & - & over-cautious & $\begin{array}{c}\text { significant loss of } \\
\text { time }\end{array}$ \\
\hline "yellow" & "indication" & standard & - \\
\hline "yellow hook" & "limit" & limit & $\begin{array}{c}\text { risk of } \\
\text { overspeeding }\end{array}$ \\
\hline
\end{tabular}

The "dark grey" driving style is over-cautious. The goal of such kind of driver is to always run with "dark grey" CSG and grey speed pointer. Such drivers anticipate the speed reduction order and reduce pro-actively the speed of their train.

The "yellow" driving style is adequate with the ERTM/ETCS braking curve philosophy. The driver reduces significantly the speed of the train only when the 
yellow colour is displayed and the Sinfo sound is played. When applying this driving style, the actual speed stays slightly under the permitted speed until the target speed is reached.

The "yellow hook" driving style is not a good practice. Running at "yellow hook" means to run at the decreasing permitted speed. It isn't a safe way to drive; if adhesion situation is weaker than expected, the deceleration effort may not be sufficient, and the orange colour could rapidly turn into the red one, indicating a system brake intervention.

\section{Some options to display Speed Advice/Guidance on the ETCS-DMI}

The purpose of speed advices or speed guidance is not to distract drivers from safety information.

Therefore, speed advices or guidance must not be shown as soon as the ETCSDMI displays an "Indication" (Yellow) or a "Overspeed/Warning" (Orange) status. In this paper the "DAS colour" is supposed to be Green (cf. figure 3).

The AG1 option is already in use today [2]. It uses a text indication presented in the Monitoring Area (ETCS-DMI - E-Area).

The AG2 option was presented with some making variants in [3]. Advice/Guidance is presented in the Supplementary Speed Info Area (figure 2).

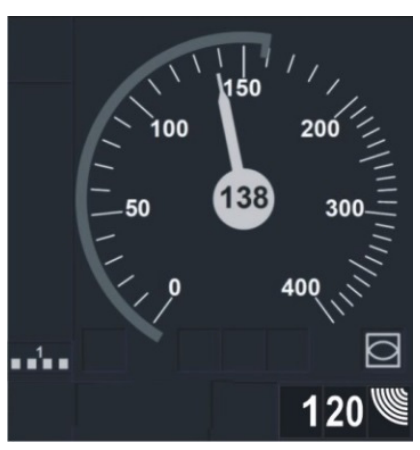

\begin{tabular}{|c|c|c|}
\hline $\begin{array}{l}\text { Colour and } \\
\text { meaning }\end{array}$ & $\begin{array}{c}\text { "grey_shade" } \\
\text { option }\end{array}$ & $\begin{array}{l}\text { "grey-white" } \\
\text { option }\end{array}$ \\
\hline no advice & $\begin{array}{c}\text { Dark blue } \\
\text { (background) }\end{array}$ & $\begin{array}{c}\text { Dark blue } \\
\text { (background) }\end{array}$ \\
\hline $\begin{array}{l}\text { Speed to be } \\
\text { gradually } \\
\text { reached }\end{array}$ & $\begin{array}{l}\text { Medium } \\
\text { Grey }\end{array}$ & Grey \\
\hline $\begin{array}{l}\text { Speed to be } \\
\text { rapidly } \\
\text { reached }\end{array}$ & Grey & White \\
\hline $\begin{array}{l}\text { Speed to be } \\
\text { maintained }\end{array}$ & Dark Grey & $\begin{array}{l}\text { Medium } \\
\text { Grey }\end{array}$ \\
\hline
\end{tabular}

Figure 2: Option AG2 - CGTO - Example: $120 \mathrm{~km} / \mathrm{h}$ to be reached rapidly ("grey-white" option / Advice from TMS / ETCS L1 FS).

Unfortunately, in ETCS baseline 3, the Supplementary Driving Info Area has no place anymore to present speed advice/guidance [1].

The AG3 option uses O_TSR displayed in the Planning area (ETCS-DMI - DArea). Advice - or even guidance - is transmitted from TMS to DMI (cf. figure 3).

Like AG3, the AG4 option uses O_TSR displayed in the Planning area (ETCSDMI - D-Area). O_TSR is also displayed in the Speed info area (ETCS-DMI - CArea) by painting in green the CSG from bottom to V_OTSR as long as the train is under the CSM NoS supervision or the TSM IndS supervision with actual speed under Vtarget. 


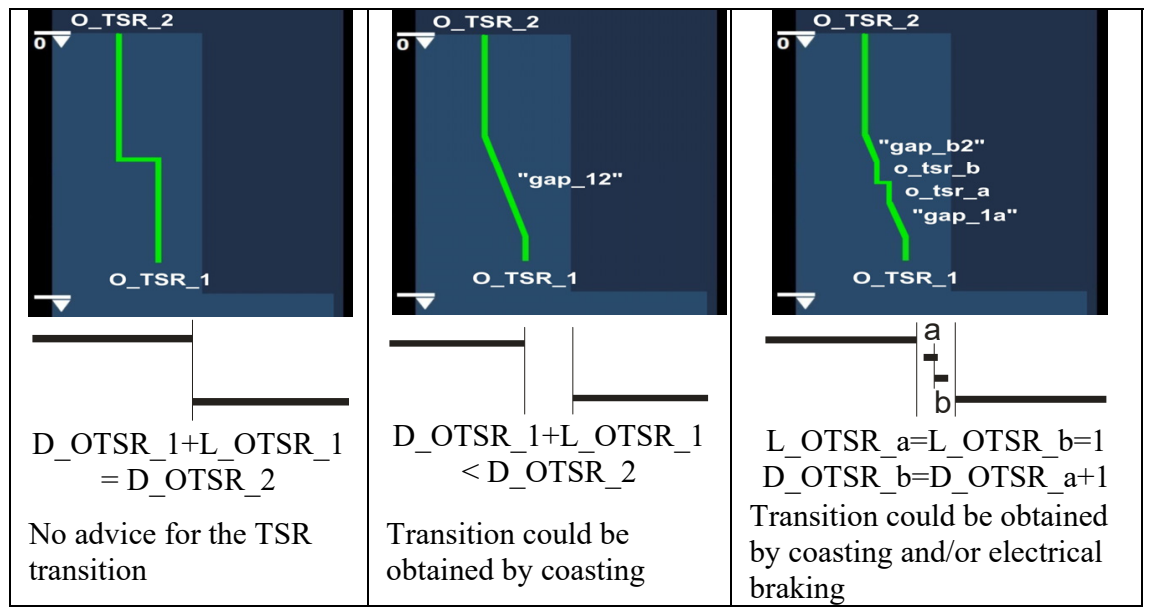

Figure 3: Option AG3 -advice/guidance in the ETCS-DMI PASP part.

\section{Tentative of displaying Operational Speed Order on the ETCS-DMI}

In this last family of options, O_TSR are considered to draw the ETCS Static and Dynamic Speed Profiles and then to build the braking curves. These following options differ only on the information given to the driver.

Within the O5 option the driver cannot distinguish O_TSR from TSR due to safety reasons.

Within the O6 option the driver can distinguish O_TSR from other TSR only in the Planning area (cf. figure 3 ).

Within the 07 option the driver can distinguish O_TSR from other TSR in the Planning area like option O6 (cf. figure 3, left). O_TSR is also displayed in the Speed info area by painting in green the CSG from bottom to V_OTSR as long as the train runs with the Normal status (NoS).

\section{Implementation for speed advice, guidance or order}

As mentioned earlier, O_TSR is the means to transmit speed advice, guidance or order. The ERTMS on-board system must then distinguish two new "messages": "Operational Temporary Speed Restriction" and "Operational Temporary Speed Restriction Revocation".

The first will be similar, in structure, to the ETCS packet 65 "TSR" and the last similar to the ETCS packet 66 "TSR revocation".

\subsection{Attempt with ERTMS baseline 3}

Packets 65 (TSR) and 66 (TSR Revocation) use the identity number of the TSR NID_TSR ( 8 bit length). It could be possible to reserve specific values of NID_TSR to transmit O_TSR, by example [11000001-11110111] $=[193-239]$. 
If the onboard system is not able to distinguish between TSR and O_TSR, both will be considered as TSR and safety is ensured.

However, it is quite important that the Traffic Management System (TMS) is aware that specific NID_TSR are used for O_TSR and not for standard TSR in order not to send a TSR which will be interpreted on board as an O TSR. One possible mechanism to inform the onboard unit the TMS consciously uses O_TSR is to send a very particular and illogical TSR just before an O_TSR in the same message. For example, this TSR could contain V_TSR $=[1110001]=[113]$ which mean a TSR at $565 \mathrm{~km} / \mathrm{h}$.

\subsection{Alternative attempt with a future ERTMS baseline}

The easiest way is to create two new packets (cf. SUBSET-026-7 v300); packets 165 and 166 (cf. table 5) for example.

Table 5: O_TSR - new ETCS packets 165 and 166.

\begin{tabular}{|c|c|c|c|}
\hline \multicolumn{2}{|c|}{$\begin{array}{l}\text { Transmission of temporary speed } \\
\text { restriction (packet 165) }\end{array}$} & \multicolumn{2}{|c|}{$\begin{array}{l}\text { Transmission of temporary speed } \\
\text { restriction revocation (packet 166) }\end{array}$} \\
\hline Variable & Length & Variable & Length \\
\hline NID_PACKET & 8 & NID_PACKET & 8 \\
\hline Q_DIR & 2 & Q_DIR & 2 \\
\hline L_PACKET & 13 & L_PACKET & 13 \\
\hline Q SCALE & 2 & NID OTSR & 8 \\
\hline NID_OTSR & 8 & & \\
\hline D OTSR & 15 & & \\
\hline L_OTSR & 15 & & \\
\hline Q FRONT & 1 & & \\
\hline V OTSR & 7 & & \\
\hline
\end{tabular}

\section{Short and very specific glossary, abbreviations and acronyms}

Centrally Guided Train Operation Systems: Driver Advice Systems (DAS) receiving Speed Advice continuously or semi-continuously from the track-side Traffic Management System (TMS). This term was used in the FP7 European Research Project "ON TIME” [4].

Operational Temporary Speed Restrictions: Speed Restrictions varying rapidly in space and time. They are not given for safety raisons but mainly for more fluid traffic.

Speed Advice: Discrete speed indication given in advance to the driver. The driver can decide freely how to comply with the advice. No system intervention is foreseen if the driver ignores the advice.

Speed Guidance: Speed indications given in advance to the driver. The guidance can be continuous or semi-continuous (target speed and tactic to reach it). No system intervention is foreseen if the driver ignores the guidance as long as the train runs under the safe speed profile.

Speed Order: Speed indications given in advance to the driver. The order shall be obeyed by the driver. If not, a system intervention brakes the train. 
Table 6: Abbreviations and acronyms.

\begin{tabular}{|c|c|c|c|}
\hline ATO & $\begin{array}{l}\text { Automatic Train } \\
\text { Operation }\end{array}$ & MRDSP & $\begin{array}{l}\text { Most Restrictive } \\
\text { Dynamic Speed Profile }\end{array}$ \\
\hline ATP & Automatic Train & NoS & Normal Status \\
\hline & Protection & NTC & National Train \\
\hline CGTO & $\begin{array}{l}\text { Centrally Guided Train } \\
\text { Operation System }\end{array}$ & OvS & $\begin{array}{l}\text { Control System } \\
\text { Overspeed Status }\end{array}$ \\
\hline CSG & Circular Speed Gauge & O_TSR & Operational Temporary \\
\hline CSM & Ceiling Speed & & Speed Restriction \\
\hline DMI & $\begin{array}{l}\text { Monitoring } \\
\text { Driver Machine Interface }\end{array}$ & $\mathrm{P}$ & $\begin{array}{l}\text { Permitted Speed/Decel. } \\
\text { (braking curve) }\end{array}$ \\
\hline EBI & $\begin{array}{l}\text { Emergency Brake } \\
\text { Intervention (brak. curve) }\end{array}$ & PASP & $\begin{array}{l}\text { Planning Area Speed } \\
\text { Profile }\end{array}$ \\
\hline $\begin{array}{l}\text { EoA } \\
\text { ERTMS }\end{array}$ & $\begin{array}{l}\text { End of Authority (ETCS) } \\
\text { European Railway Train }\end{array}$ & $\mathrm{RBC}$ & $\begin{array}{l}\text { Radio Block Centre } \\
\text { (GSM-R) }\end{array}$ \\
\hline & $\begin{array}{l}\text { Management System } \\
(=\mathrm{ETCS}+\mathrm{GSM}-\mathrm{R}+\mathrm{ETML})\end{array}$ & $\begin{array}{l}\text { RS } \\
\text { RSM }\end{array}$ & $\begin{array}{l}\text { Rolling Stock } \\
\text { Release Speed }\end{array}$ \\
\hline ETCS & $\begin{array}{l}\text { European Train } \\
\text { Control System }\end{array}$ & RU & $\begin{array}{l}\text { Monitoring section } \\
\text { Railway Undertaking }\end{array}$ \\
\hline ETML & $\begin{array}{l}\text { European Train } \\
\text { Management Layer }\end{array}$ & SATO & $\begin{array}{l}\text { Semi-Automatic } \\
\text { Train Operation }\end{array}$ \\
\hline EVC & $\begin{array}{l}\text { European Vital } \\
\text { Computer (on-board) }\end{array}$ & SBMD & $\begin{array}{l}\text { System Brake Maximal } \\
\text { Deceleration (braking }\end{array}$ \\
\hline FS & Full Supervision & & curve) \\
\hline GSM-R & $\begin{array}{l}\text { Global System for Mobile } \\
\text { communications - } \\
\text { Railways }\end{array}$ & Sinfo & $\begin{array}{l}\text { Standardised information } \\
\text { sound ( } 2 \text { identical } \\
\text { short and close sounds) }\end{array}$ \\
\hline GUI & $\begin{array}{l}\text { Guidance Speed/Decel. } \\
\text { (braking curve) }\end{array}$ & SvL & $\begin{array}{l}\text { Supervised Location } \\
\text { (ETCS) }\end{array}$ \\
\hline HS & High Speed & TMS & Traffic Management \\
\hline HSL & High Speed Line & & System \\
\hline I & Indication Curve & TSI & Technical Specification \\
\hline IM & Infrastructure Manager & & for Interoperability \\
\hline IndS & Indication Status & TSR & Temporary Speed \\
\hline IntS & Intervention Status & & Restriction \\
\hline IXL & Interlocking & TSM & Target Speed Monitoring \\
\hline KVB & $\begin{array}{l}\text { Contrôle de Vitesse } \\
\text { par Balise }\end{array}$ & $\begin{array}{l}\text { WaS } \\
\text { ZUB }\end{array}$ & $\begin{array}{l}\text { Warning Status } \\
\text { ZUg Beeinflussung }\end{array}$ \\
\hline MRSP & $\begin{array}{l}\text { Most Restrictive static } \\
\text { Speed Profile }\end{array}$ & & \\
\hline
\end{tabular}

\section{Conclusion}

AG3, AG4 as well as O7 options are simple to implement. Information about O_TSR is simple and mainly given in the ETCS-DMI Planning area.

Those implementation propositions can likely by adopted by Railway Undertakings and Infrastructure Managers at a European wide level. 


\section{References}

[1] ERA, ETCS Driver. Machine Interface, ERA_ERTMS_015560, V.3.5.0, December 2015.

[2] Mehta, F., Rössiger, C., Montigel, M., Potenzielle Energiesparnis durch Geschwindigkeitempfehlungen im Bahnverkehr, (102) 9/2010 Signal+Draht, pp. 20-26, 1985.

[3] Emery, D., Towards a versatile European Driver Advisory System, Proc. of the $14^{\text {th }}$ Conf. on Computer System Design and Optimization (Comprail XIV), eds C.A. Brebbia and others, pp.365-374, WIT Press, Southampton, 2014.

[4] DB Netz, DAS-Requirements_and_System_Designs, Optimal Networks for Train Integration Management across Europe (ON-TIME - WP 6 - Internal paper), 2012. 